\title{
HERRAMIENTAS ESPACIALES PARA LA MEJORA DE LA GESTIÓN DE LA INFORMACIÓN EN ALERTA SANITARIA POR COVID-19
}

\author{
María Zúñiga Antón \\ Dpto. Geografía y Ordenación del Territorio \\ Universidad de Zaragoza \\ Ángel Pueyo Campos \\ Dpto. Geografía y Ordenación del Territorio \\ Universidad de Zaragoza \\ Raúl Postigo Vidal \\ Escuela Universitaria de Turismo de Zaragoza
}

La pandemia COVID-19 está considerada como la tragedia de salud mundial más crítica del siglo y el mayor desafío que la humanidad ha enfrentado desde la Segunda Guerra Mundial (Chakraborty \& Maity, 2020) aunque han sido varias las epidemias y pandemias sucedidas desde el año 2.000 (OMS, 2020a).

En diciembre de 2019, surge un nueva enfermedad que afectaba al sistema respiratorio en Wuhan, provincia de Hubei (China) y fue nombrada por la Organización Mundial de la Salud como COVID-19: CO de Corona VI de virus, D disease y 19 haciendo referencia al año de identificación (OMS, 2020b). El responsable de la aparición de esta enfermedad es el coronavirus de tipo 2 causante del síndrome respiratorio agudo severo, conocido como SARS-CoV-2.

Los países se encuentran en etapas diferentes de brotes nacionales y subnacionales. Allí donde se han tomado acciones tempranas y se han implantado medidas de salud pública integrales, como la identificación rápida de casos, las pruebas y el aislamiento rápido de los casos, el rastreo completo y la cuarentena de los contactos, se ha contenido el brote de COVID-19 por debajo del umbral en el cual los sistemas sanitarios son incapaces de evitar el exceso de mortalidad. Los países que han podido reducir la transmisión y controlar el brote han mantenido la capacidad para ofrecer atención clínica de 
calidad y minimizar la mortalidad secundaria debida a otras causas mediante la prestación de los servicios sanitarios esenciales de forma continuada y en condiciones seguras. En muchos países en los que la transmisión comunitaria ha generado brotes con crecimiento casi exponencial, se han introducido medidas generalizadas de distanciamiento físico a nivel de la población y restricciones de movimiento para frenar la propagación.

La pandemia por COVID-19 está llena de incógnitas, muchas de las cuales tienen una dimensión espacial que lleva a entender el fenómeno como geográfico y potencialmente cartografiable. Así pues, las necesidades de investigación incluyen: la capacidad de combinar variables de diferentes tipos para interpretar el fenómeno COVID-19 y anticiparse al mismo, el avance hacia su análisis espacial y temporal, la evaluación de su impacto en la vida cotidiana, y la elaboración de modelos predictivos de la evolución de la enfermedad (Franch-Pardo, Napoletano, Rosete-Verges, \& Billa, 2020). En definitiva, la Geografía puede responder a esta crisis sanitaria de diversas maneras (Castree et al., 2020).

En este contexto el Grupo de Estudios en Ordenación del Territorio (GEOT) del Departamento de Geografía de la Universidad de Zaragoza en colaboración con la Catedra Territorio, Sociedad y Visualización Geográfica, con el Ayuntamiento de Zaragoza y con el Instituto Geográfico de Aragón, han trabajado desde junio de 2020 en el proyecto de investigación titulado: "Desarrollo de Herramientas geoespaciales de apoyo para la mejora de la gestión de la información en alerta sanitaria del COVID-19 y su posterior gestión epidemiológica, social y económica". Este proyecto ha sido financiado por la convocatoria competitiva Programa COVID19/Mecenazgo BANCO SANTANDER-UNIZAR. y tiene dictamen favorable del Comité de Ética de la Investigación de la Comunidad Autónoma de Aragón desde septiembre de 2020.

El proyecto tiene como objetivo general ofrecer protocolos de trabajo que integren el tratamiento masivo de información social, económica y sanitaria para su posterior análisis y representación multiescalar mediante cartografía temática, sirviendo de base para el desarrollo de políticas de gestión sanitaria, social y económica que mitiguen/ supriman los efectos de COVID-19.

Los resultados de este proyecto se publican a través de mapas y visores interactivos publicados por el Ayuntamiento de Zaragoza en el Visor Demográfico (Ayuntamiento de Zaragoza, 2020), el Gobierno de Aragón en el Atlas de Salud gestionado por el Instituto Geográfico de Aragón (Gobierno de Aragón, 2017) y la página web del Instituto Universitario de Ciencias Ambientales (IUCA) de la Universidad de Zaragoza (Instituto Universitario Ciencias Ambientales UNIZAR, 2020).

Como parte del plan de difusión y transferencia de conocimiento cada semana se publican los mapas que muestran la Tasa de Frecuentación COVID-19. Esta se entiende como el número de pacientes infectados o con sospecha de estar infectados según registro de los Centros de Salud Públicos por 100.000 habitantes mediante leyendas se- 
cuenciales de color-valor y el total de esos pacientes mediante la variable visual tamaño (Figura 1). En un segundo mapa se representa la Tasa de variación porcentual de cada semana, lo que permite estimar la evolución de la enfermedad en cada momento. Ambos mapas se realizan para la ciudad de Zaragoza y también para la Comunidad Autónoma de Aragón (Figura 2).
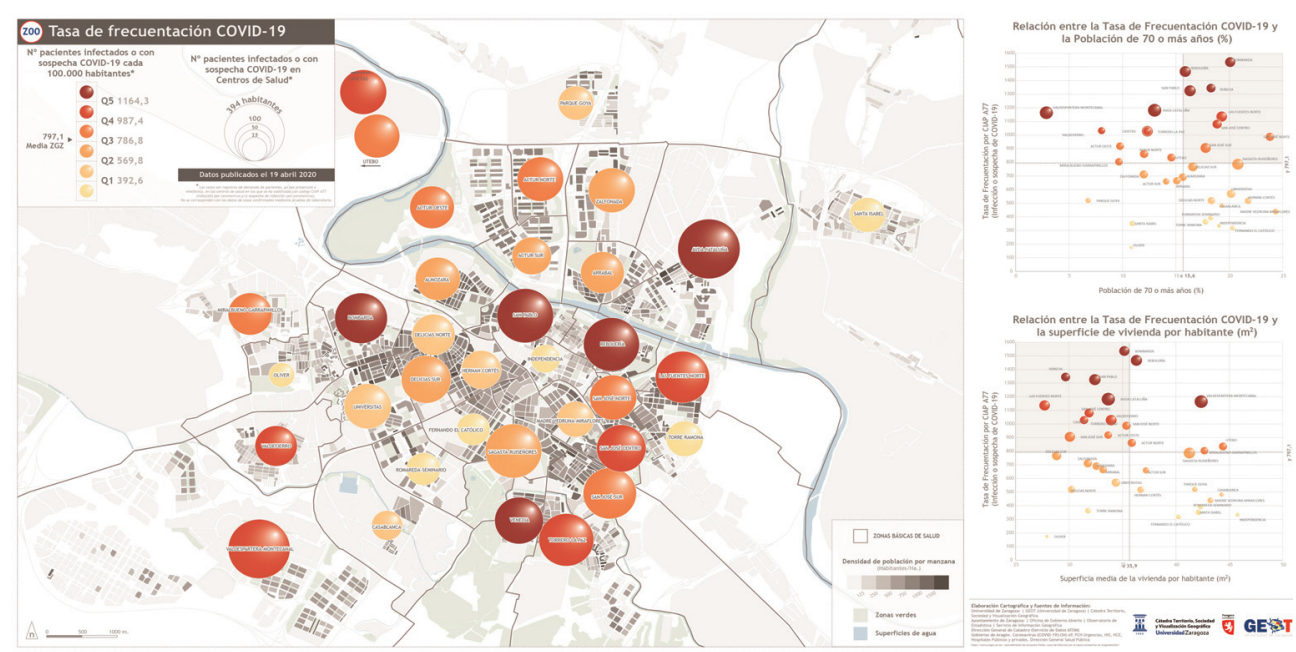

Figura 1. Mapa de Tasa de Frecuentación en la ciudad de Zaragoza.

Fuente: Elaboración Grupo GEOT.

De manera adicional se han preparado diversas series cartográficas agrupadas por diferentes temáticas: concentración y hacinamiento de la población, estructura de edad, actividad de la población, estudio de comorbilidades, análisis de hogares y grados de formación.

En ellas se representan los indicadores más habituales, como es la densidad de población o las tasas de envejecimiento, combinados con indicadores más específicos como es la distribución por la población teniendo en cuenta los metros cuadrados por habitante y las viviendas de 90 metros o menos en las que residen 5 o más personas. Son informaciones que se presentan a varias escalas por una parte la de Zonas Básicas de Salud, que es la unidad de gestión de referencia utilizada por el sistema sanitario y por otra se puede descender hasta nivel de manzana, lo que permite un análisis mucho más detallado. 


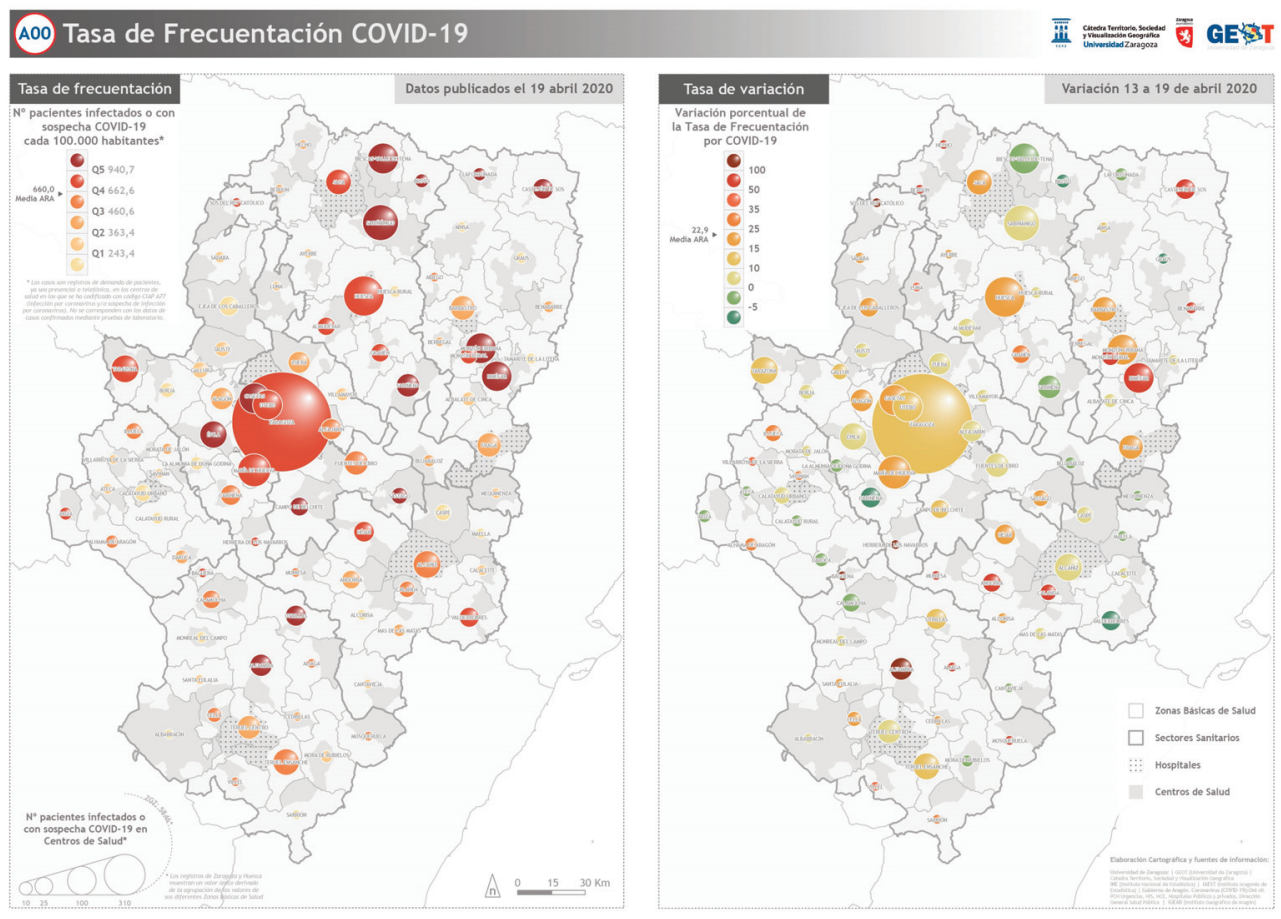

Figura 2. Mapa de Tasa de Frecuentación y Mapa de variación de Tasa de Frecuentación en Aragón.

Fuente: Elaboración Grupo GEOT.

\section{Bibliografía}

Ayuntamiento de Zaragoza. (2020). Visor Demográfico (Datos COVID-19). Retrieved December 12, 2020, from https://www.zaragoza.es/sede/portal/coronavirus/geocovid19

Castree, N., Amoore, L., Hughes, A., Laurie, N., Manley, D., \& Parnell, S. (2020). Boundless contamination and progress in Geography. Progress in Human Geography, 44(3), 411-414. https:// doi.org/10.1177/0309132520920094

Chakraborty, I., \& Maity, P. (2020). COVID-19 outbreak: Migration, effects on society, global environment and prevention. Science of the Total Environment, 728, 138882. https://doi.org/ 10.1016/j.scitotenv.2020.138882

Franch-Pardo, I., Napoletano, B. M., Rosete-Verges, F., \& Billa, L. (2020). Spatial analysis and GIS in the study of COVID-19. A review. Science of the Total Environment, 739. https:// doi.org/10.1016/j.scitotenv.2020.140033

Gobierno de Aragón. (2017). Atlas de Salud de Aragón. Retrieved December 12, 2020, from https://idearagon.aragon.es/atlas/indexSalud.jsp 
Instituto Universitario Ciencias Ambientales UNIZAR. (2020). IUCA. Retrieved December 12, 2020, from http://iuca.unizar.es/

OMS. (2020a). Major infectious threats in the 21st Century. Retrieved July 10, 2020, from https:// www.who.int/images/default-source/departments/epi-win/infodemic-management/wer-timeline.jpg?sfvrsn=d7e5c32c_4

OMS. (2020b). Naming the coronavirus disease (COVID-19) and the virus that causes it. Retrieved July 10, 2020, from https://www.who.int/emergencies/diseases/novel-coronavirus-2019/technical-guidance/naming-the-coronavirus-disease-(covid-2019)-and-the-virus-that-causes-it 
